\title{
Effects of Monological and Sophrological Trainings on the Development of Attention and Retention in Tunisian Male Kick Boxers
}

\author{
Maamer Slimani ${ }^{1}$, Abdelaziz Hentati ${ }^{2}$, Majdi Bouazizi ${ }^{1}$, Driss Boudhiba ${ }^{2}$, \\ Imène Ben Amar ${ }^{2}$ and Foued Chéour ${ }^{3}$ \\ ${ }^{I}$ Faculty of Sciences of Bizerte, Tunisia \\ ${ }^{2}$ High Institute of Sport and Physical Education of Sfax, Tunisia \\ ${ }^{3}$ Thesis supervisor. High Institute of Applied Biology of Médenine, Tunisia
}

\begin{abstract}
This study aims to evaluate the effects of mental training on the development of attention and retention skills in Tunisian male kick boxers. Hundred and twenty athletes, with homogeneous age $(22 \pm 2.3$ years), height $(1.74 \pm 0.08 \mathrm{~m})$ and weight $(65 \pm 10.2 \mathrm{~kg})$ were selected for the study. They were divided into three groups of forty subjects; the first two have been submitted to the monological or sophrological training and the last served as a control. Our results have shown that both mental training types improve the above cited criteria in athletes. However, the effects were much more pronounced with sophrological treatment. We conclude that monology and sophrology can be two effective methods for optimizing the attention and retention levels in Tunisian male kick boxers but the latter is more effective.
\end{abstract}

Keywords: Mental training; monology; sophrology; attention; retention; kick boxers

\section{Introduction}

Sports, individual or collective, is a set of physical activities that improve the health and the well being of humans (Aquatias et al., 1999). These can sometimes be part of sports competitions and so involving a variety of athletic training methods to further improve the technical, physical etc.. and this to excel and be better (Souissi et al., 2013). However, it has always proved that even if they are developed and better on the above points, a lack of concentration could often be the cause of the failure of athletes (Feltz and Landers, 1983). Therefore, mental capacity could be partially or completely remedy the situation and further improve the psychic presence during competitions and this does often ensure the success or results. In some cases, increased mental preparation may also meet certain technical and physical impairments in athletes and therefore ensures success (Abadie and Andrieu, 2007; Arnous, 2012; Greenspan and Feltz, 1989).

Mental training refers to the process training with targets and plans to influence athletes' mental process and personality, adjusting and controlling their own sports behaviours by adopts social ways to promote psychological state (Xiong, 2012). Its principle is based on the mental strengthening of the athlete before and even during the competition and this to raise its concentration and improve the attention and retention levels (Abadie and Andrieu, 2007; Bolliet et al., 2005; Cogan and Retrie 1995; Collet et al., 1999; Knight, 1989; Rodgers et al., 1991; Savoy, 1997). Various methods of mental training of athletes are being used citing among them the sophrology and monology that help improve respectively imaging levels and eliminate partially or totally the lack of self-confidence (Calmels and Fournier, 1999).

The objective of this study was to compare the effects of monological and sophrological trainings, known to be excellent methods of mental preparation, on the attention and retention skills in Tunisian male kick boxers.

Kick boxers and methodology

\section{Materials and methods}

Hundred and twenty volunteers' Tunisian male professional kick boxers have been carefully selected to participate in the study. Their averages age, height and weight were respectively ordered as following: $22 \pm 2.3$ years, $65 \pm 10.2 \mathrm{~kg}$ and $1.74 \pm 0.08 \mathrm{~cm}$. They were divided into three groups of forty subjects; the first two have been submitted to the monological or sophrological training and the last served as a control. Athletes' attention and retention levels were always evaluated before and after each treatment.

\section{Monological and sophrological reinforcements}

Tunisian male kick boxers were submitted to monological or sophrological training before assessing the effects on the development of attention and retention. The sophrological reinforcement of athletes who lasted twelve weeks consisted of relaxing training and boosting (Edith 1997). However, those of monological, 
which took place before and after each training and competition, were summarized by striking initially negative thoughts naysayers of sports, and subsequently setting for five minutes in a constructive spirit for more energy motivation.

\section{Criteria of evaluation}

The attention of athletes was assessed according to the Stroop test which consists of measuring the overall time needed to characterize and read four different colours and words simultaneously (Stroop, 1935). Retention was estimated by imposing to the kick boxers a chain of 20 technical movements in the form of 'Shadow boxing'. Every successful action is rewarded by note 1. The final score awarded for each athlete corresponded to the number of successful gestures.

\section{Data analysis}

The analysis of variance (ANOVA) of results was made following a randomly complete block design (Snedecor and Cochran, 1957) by the GLM procedure of the SAS statistical package (SAS Institute, 1989). Homogeneity of variance was verified by the standard Bartlett test (Anderson and McLean, 1974). Each treatment was repeated 40 times.

\section{Results}

Figures 1 and 2 show the effects of sophrological or monological training on the evolution of the reaction time, an estimated of the attention, and the retention in Tunisian male kick boxers.

Overall, the mental training, disregarding of its nature, significantly reduces the reaction time needed for the kick boxers to characterize the colours and to read the words ( $\mathrm{P} \leq 0.001$; Fig. 1). However, this effect was more important for the athletes who were submitted to sophrological treatment $(\mathrm{P} \leq 0.001)$.

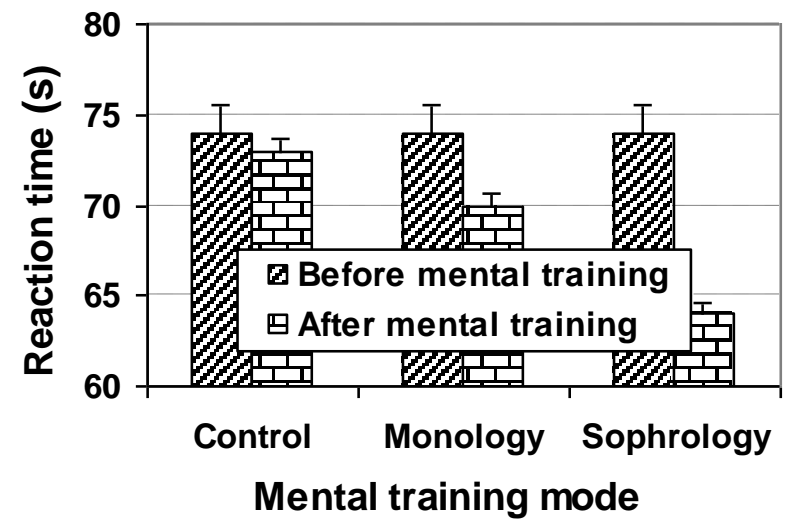

Figure 1. Evolution, according to the mental training mode, of attention levels in Tunisian male kick boxers. Vertical bar shows average \pm SD for 40 replicates.

Retention capacity increases significantly in Tunisian male kick boxers after monological or sophrological training ( $\mathrm{P} \leq 0.001$; Fig. 2). However, this effect was more pronounced in athletes who were submitted to sophrological treatment $(\mathrm{P} \leq 0.001)$.

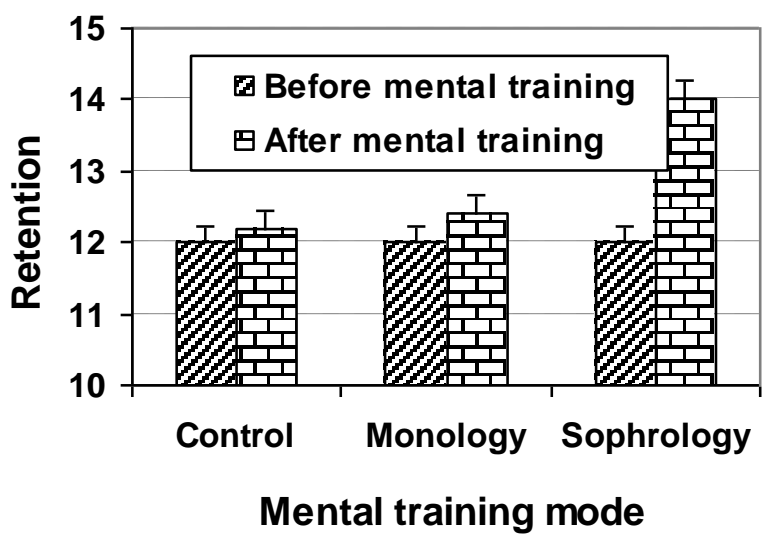

Figure 2. Evolution, according to the mental training mode, of retention levels in Tunisian male kick boxers. Vertical bar shows average \pm SD for 40 replicates. 


\section{Discussion}

Mental training is a set of techniques that the athlete learns and applies independently to maximize its chances of success in individual and team competitions and this by improving their attention and retention skills. To do this, it has various forms of exercises and methods that are most frequently encountered dynamic sophrology and inner monology (Abadie and Andrieu, 2007; Arnous, 2012; Baert and Dufour, 2007; Collet et al., 1999; Retrie and Cogan, 1995; Rodgers et al., 1991).

Our study showed that the mental concentration in Tunisian male kick boxers, as reflected by an enhancement in attention and retention, increases due to monological or sophrological reinforcement. This corroborates with the study of Collet $e t$ al. (1999) who reported that mental training further improves alertness and athletes' driving performance. However, it appears that the sophrology was better on the above parameters. Indeed, the sophrology is a relaxing treatment that promotes the development of imaging capability, the main factor affecting attention and retention that are real assets of the success, of athletes through motor skills and involves the right hemisphere of the brain. However, the monology does only temporarily raises the selfconfidence levels, and this by eliminating negative thoughts and defeatist, and the development in a constructive spirit to have more energy of motivation (Abadie and Andrieu, 2007).

In conclusion, the monology and sophrology can be two effective relaxation methods for improving the attention and retention levels in Tunisian male kick boxers during competitions. A combination of these two techniques in mental training could further that optimizing the aforementioned effects.

\section{Références}

[1]. Abadie S., Andrieu B. 2007. Proprioception et représentation mentale. Une dialectique dans la préparation mentale des sportifs de haut-niveau. Revue françaises de psychiatrie et de psychologie médicale, 11: 21-25.

[2]. Anderson VL., McLean RL. 1974. Design of experiments. Marcel Dekker, New York

[3]. Aquatias S., Desrues I., Leroux M., Stettinger V., Valette-Viallard C. 1999. Activités sportives, pratiques à risques, usages de substances dopantes et psychoactives : recherche sur la pratique moderne du sport. Resscom, Ministère de la Jeunesse et des Sports, 12: $9-11$

[4]. Arnous A. 2012. The Effect of the type of Sports' mattresses on developing mental skills and tactics for junior fencers. Procedia Engineering, 34: 861-865

[5]. Bolliet O., Collet C., Dittmar A. 2005. Autonomic nervous system activity during actual and mentally simulated preparation for movement. Applied Psychophysiology and Biofeedback, 30: 11-20.

[6]. Chevalier N. 1989. L'imagerie dans l'entraînement mentale des sportifs : une application ski de fond. Revue québécoise de psychologie, 10: 151-168.

[7]. Cogan KD., Retrie TA. 1995. Sport consultation: An evaluation of a season-long intervention with female collegiate gymnasts. The Sport Psychologist, 9: 286-296.

[8]. Collet C., Roure R., Dittmar A. 1999. Conférence: Colloque "Biologie de l'exercice musculaire", 2, Clermont-Ferrand, FRA. Science et sports, 15: 261-263.

[9]. Edith PP. 1997. Sophrologie et performance sportive, Guide pratique. Amphora, 12: 125-133.

[10]. Feltz DL., Landers DM. 1983. The effects of mental practice on motor skill learning and performance: a meta-analysis. Journal of Sport Psychology, 5: 25-57.

[11]. Gaudreau P., Sanchez X., Blondin JP. 2006. Positive and negative affective states in a performance-related setting. Testing the factorial structure of the PANAS across two samples of French-Canadian participants. European Journal of Psychological Assessment, 22: 240-249.

[12]. Greenspan MJ., Feltz DL. 1989. Psychological interventions with athletes in competitive situations: a review. The Sport Psychologist, 3: 219-236

[13]. Rodgers W., Halla C., Buckolza E. 1991. The effect of an imagery training program on imagery ability, imagery use figure skating performance. Journal of applied Sport Psychology, 3: 109-125.

[14]. Savoy C. 1997. Tow individualized mental training program for a team sport. International Journal of Sport Psychology, 28: 257270 .

[15]. Simons DJ., Levin DT. 1997. Change Blindness. Trends in Cognitive Science, 1: 261-267.

[16]. SAS Institute. 1989. SAS/STAT User's Guide, ver. 6, vol. 2, 4th ed. SAS Institute, Cary, N.C.

[17]. Snedecor GW., Cochran WG. 1957. Statistical Methods. 6th ed. Iowa State Univ. Press.

[18]. Souissi S., Chalghaf N., Azaiez F., Chéour F. 2013. Effects of eccentric strength training's time on daily plasma testosterone levels among Tunisian sedentary athletes. IOSR Journal of Pharmacy and Biological Sciences, 2: 69-72.

[19]. Stroop JR. 1935. Studies of interference in serial verbal reactions. Journal of Experimental Psychology, 18: 643-662

[20]. Xiong J. The functions and methods of training on competitive sports. Physics Procedia, 33: 2011-2014. 